\title{
La formación de los sectores dominantes locales. Río Negro (Norpatagonia) a principios del siglo $\mathrm{XX}^{*}$
}

María E. Argeri
IEHS-UNCPBA
TANDIL, ARGENTINA

Se analizan los mecanismos políticos y la conflictividad en la constitución embrionaria de los sectores dominantes locales en un espacio norpatagónico.

$\mathrm{H}$ asta hace pocos años, la historiografía que abordaba la construcción y consolidación de los Estados-nación en América Latina, analizaba dichos procesos teniendo solamente en cuenta las confrontaciones entre las elites, los pactos intraoligárquicos y la modernización democrática de fines del siglo XIX. Sin embargo, hoy se ha abierto un amplio

*Título original, "El difícil equilibrio entre el ejercicio de la violencia personal y la política federal en la formación de los sectores dominantes locales. Río Negrọ (Norpatagonia) a principios del siglo XX". debate en torno a estas perspectivas, enriqueciéndose con el análisis político, a partir de estudios que centran la atención en otros actores sociales -campesinos, poderes locales y regionales, asociacionismo republicano y popular, etc. - y con los diferentes planos de confrontación social y étnica. ${ }^{1}$

Siguiendo esta vía de análisis, en el presente trabajo se pretende mostrar

\footnotetext{
${ }^{1}$ En esta perspectiva véase, Bonaudo y Sonzogni, "Redes", 1992, pp. 74-110; Graham, $\mathrm{Pa}$ tronage, 1990; Guerra, México, 1988; Rendón, Prosperato, 1993; Mallon, Peasant, 1995; Sábato, "Ciudadanía", 1992; Thomson, "Popular", pp. 265-292.
} 
cuáles fueron los mecanismos políticos mediante los cuales se conformaron los sectores dominantes locales en su etapa embrionaria, caracterizados por instancias de poder personal, mismos que se tornaron, al mismo tiempo, funcionales y contradictorios con la dimensión política federal. El espacio social seleccionado es el territorio de Río Negro, situado en la Norpatagonia y dependiente del gobierno federal desde fines del siglo XIx hasta su provincialización en la década de 1950. Cabe señalar que los territorios que se pusieron bajo esta condición administrativa -tanto en el noroeste chaqueño como en el sur pampeano patagónicofueron los que se ocuparon por conquista, luego de la guerra final contra las naciones indias (1879-1885).

En los espacios patagónicos, comenzaban a perfilarse, al iniciarse el siglo $\mathrm{xx}$, los primeros entramados de poder local, donde los comisarios jugaron un papel decisivo en la articulación de las redes sociales y en la preponderancia que unas podían alcanzar sobre las otras. Pero el uso y la amenaza de violencia conducían a frecuentes enfrentamientos, situación que dio por resultado configuraciones de poder lábiles e inestables, en todo el territorio, hasta bien entrado el presente siglo.

Para ilustrar este tipo de conflictividad, se hará referencia a la guerra de comisarios que tuvo como epicentro a la localidad rionegrina de Choele Choel (departamento de Avellaneda) durante la década de $1910^{2}$ y que repercutió en las localidades de Pringles (departa-

\footnotetext{
${ }^{2}$ La selección de este caso se debe a la mayor abundancia de información con que conta-
}

mento de Alsina) y Valcheta (departamento de 25 de Mayo), situadas en el mismo territorio. La documentación analizada pertenece a los repositorios regionales de justicia letrada, justicia de paz, gobernacion y policía.

\section{INTRODUCCIÓN}

En la primera década del siglo $\mathrm{Xx}$, en el territorio de Río Negro estallaron una serie de conflictos que asumieron la modalidad de verdaderas guerras locales, aparentemente irresolubles, entre redes sociales antagónicas estructuradas con base en el poder personal de sus miembros más prominentes. Este tipo de vinculaciones son evidentes en toda la documentación consultada: telegramas dirigidos al gobernador del territorio, instrucción de sumarios, querellas y procesos iniciados en la justicia letrada, editoriales de los periódicos locales y noticias en la prensa nacional. Los entramados de intereses se transparentan más claramente en los momentos de conflicto, en los cuales, los sujetos que integraban dichas redes quedan al descubierto mostrando la multiplicidad de contactos y compromisos.

Los escenarios de estas confrontaciones fueron los primeros núcleos poblados donde se asentó la base social primigenia de los futuros pueblos y ciudades. Y los protagonistas de ese tipo de conflictos fueron quienes integraban las fuerzas vivas: aquellos que tenían pretensión de mando. El resto

mos. Casos similares sucedieron en Buena Parada, Gral. Roca, Valcheta, Roca, etcétera. 
de los habitantes de los pueblos, como asimismo los otros pobladores del territorio -naciones indias remanente de la guerra y ocupantes pobres de tierras fiscales, desplazados de los espacios capitalistas de Argentina y Chile- que vivían dispersos en las zonas rurales propiamente dichas, permanecieron al margen de este tipo de disputas.

Las fuerzas vivas estaban compuestas, fundamentalmente, por comerciantes: dueños de almacenes de ramos generales y acopiadores de frutos del país, traficantes de ganado, bolicheros, carniceros, dueños de fondas y prostíbulos. También artesanos -herreros y carpinteros. Y los más importantes productores rurales, propietarios $\mathbf{u}$ ocupantes de grandes extensiones de tierra (que en las fuentes aparecen en la categoría bacendado). También los directores de las cárceles, los jueces de paz y los jefes de telégrafos y correos. En algunos casos, también los profesionales y curas. En los poblados donde estaban asentados los batallones, integraban asimismo el núcleo de poder los jefes militares. En su conjunto, formaban parte de la población blanca de primeros ocupantes que se internaron en el territorio luego de la guerra contra el indio, siendo relevante el número de extranjeros -en su mayoría europeos: españoles e italianos.

En todos los casos se trataba de hombres sin prosapia, recién llegados que aspiraban a acaparar recursos en una zona todavía marginal, como era la Patagonia por esos años. La competencia por el control de los circuitos mercantiles lícitos e ilícitos y el acaparamiento de las mejores tierras generaban recurrentes pujas, las cuales asu- mían una modalidad corporativa cada vez que confrontaban distintas redes sociales.

Ante la debilidad o inexistencia de funcionarios municipales ${ }^{3}$ que estuviesen por fuera de los problemas, la resolución de los conflictos que afectaban a las embrionarias fuerzas vivas se lograba mediante tres mecanismos: el uso de la violencia explícita; la apelación a los funcionarios del territorio, con asiento en la capital, Viedma; la ventilación de los hechos mediante mecanismos de intriga, publicados en la prensa local, de los cuales se hacía eco la prensa nacional, llevando directamente la información al gobierno federal. Así, los jefes de correos y telégrafos y los corresponsales de diferentes periódicos y diarios desempeñaron un papel muy importante en la tarea de hacer públicos los motivos de las confrontaciones. Para los implicados era fundamental mantener el control de las comunicaciones, hecho que se refleja en la urgencia por apoderarse, en carrera maratónica, de las oficinas del telégrafo cada vez que los conflictos estallaban.

En este contexto, los comisarios y jueces de paz se desempeñaron como articuladores fundamentales de las inestables redes de poder $y$, por tanto, en actores principales de la confronta-

\footnotetext{
${ }^{3}$ Para que un poblado turiese poder municipal debía sobrepasar los 1000 habitantes; pero a pesar de que muchos habían alcanzado dicha cifra, la legislación no era aplicada. En unas interpretaciones, la cifra de 1000 implicaba a poblado y campaña; en otras sólo al poblado. Por consiguiente existía una aplicación discrecional de la ley que el gobierno federal jugaba a su favor.
} 
ción. Durante las primeras décadas de ocupación del territorio, estas funciones públicas eran asignadas a cualquier vecino $y$, con mucha frecuencia, el cargo se sumaba a la actividad privada. La red primaria en la que se encontraba inserto el sujeto beneficiado pasaba a detentar una preeminencia temporaria, al mismo tiempo que los conflictos asumían una dimensión personalizada. Así, los jueces de paz y los comisarios se tornaron los rostros visibles de la conflictividad. La abundante cantidad de sumarios y juicios por cualquier tipo de imputación, dejó registrados sus nombres en diferentes carátulas. No obstante, en un contexto social de violencia cotidiana explícita, los jueces de paz ofrecían una manifiesta debilidad material para bascular los intereses a su favor. Las redes más sólidas se nucleaban siempre en torno a los cuadros altos de la policía, ya que a nivel local, ellos eran los sujetos que controlaban el uso legítimo de la violencia, situación que, a la hora de ejercer el poder, les otorgaba una considerable ventaja comparativa.

Las redes de poder local se sustentaban en beneficios materiales mutuos para sus miembros. Para los comerciantes y productores esto significaba resguardar y consolidar los intereses corporativos: tráfico ilícito y acaparamiento de tierras. En cuanto a los beneficios materiales que esta vinculación aportaba a los cuadros altos de los cuerpos policiales hay que destacar, en primer lugar, que los mayores comerciantes o sus agentes liquidaban los salarios en dinero o en especie (debido tanto a la tardanza que existía para librar los fondos federales, como a la costumbre de adelantar los sueldos al fiado) ${ }^{4} \mathrm{y}$, en segundo lugar, eran los consuetudinarios prestamistas y quienes, además, podían pagar un sobresueldo por concepto de los beneficios recibidos. $^{5}$

Otro elemento importante que es necesario destacar es el siguiente: la relación comerciantes-comisarios se legitimaba en disposiciones gubernamentales. Luego de sancionada la Ley Orgánica de los Territorios Nacionales (número 1534/1884), los cuerpos policiales pasaron a depender directamente del gobernador del territorio. ${ }^{6}$ Pero, los nombramientos del personal superior debían contar siempre con el visto bueno del grupo de poder local, cuyos miembros cumplían funciones en los consejos asesores de la policía.

En resumen, mediante el ejercicio de la violencia personal habían comenzado a instaurarse diferentes órdenes locales. En los pueblos, la voz de la ley eran los comisarios y sus amigos. Esta

${ }^{4}$ Archivo Histórico Provincial de Río Negro (en adelante AHPRN), Policía, UD 9730/1095. Solicitud de dos comerciantes por cobro de vales a empleados de policía por salario adelantado; UD 010100/1905. Los comerciantes de Buena Parada se niegan a adelantar los salarios por retrasos del gobierno federal en cancelar la deuda.

"Véase Argeri y Chia, "Resistiendo", 1993, pp. 275-306.

${ }^{6}$ Antes de 1884, las funciones policiales fueron desempeñadas por el ejército; este tema ha sido tratado en un trabajo anterior presentado en el Simposio Internacional Estado, Elites y Cuestión Regional, UNT, Tucumán, 1996.

${ }^{7}$ Para el caso del Río Negro la medida se hizo efectiva por decreto del gobernador Eugenio Tello-designado por el general Roca- dictado en 1898 en el momento de su asunción. AHPRN, Gobernación, UD 2075. Movimiento administrativo durante el año 1898. 


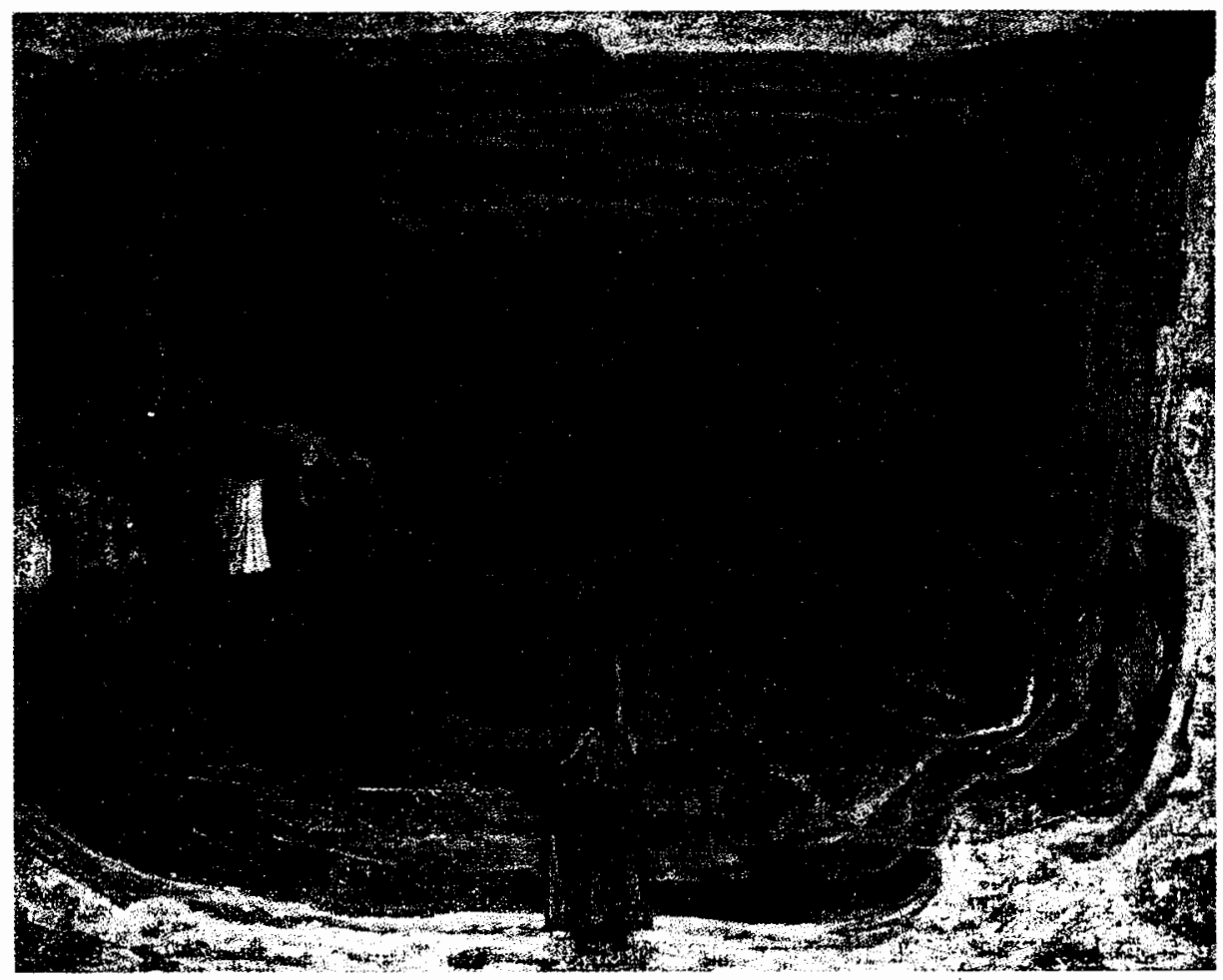

situación no sería tolerada por el poder federal. En efecto, durante la segunda presidencia de Julio A. Roca (1898-1904), se puso en práctica la rotación obligatoria de los cuadros altos de la policía, cada cinco años. El objetivo era debilitar los entramados de poder, ya que un recambio de las jefaturas implicaba, a nivel local, un reordenamiento de los pactos y una rearticulación de las redes.

Así, cuando la medida se puso en práctica por primera vez en Río Negro, a fines de 1903 , y la absoluta mayoría de los comisarios fueron dados de baja, el territorio estuvo afectado por una escalada de violencia, en la que se enfrentaron los exonerados con los nuevos funcionarios en servicio, quienes habían sido recientemente designados.

\section{LAS GUERRAS locales EN CHOELE Choel, Pringles y Valcheta}

En las confrontaciones que describiremos seguidamente, aparecen como protagonistas centrales -en calidad de imputados- los comisarios Mariano Gamboa, Ángel Bordo y Aquino Quiroga, conjuntamente con los vecinos decentes de cada localidad: las fuerzas 
vivas. En el relato se priorizarían solamente aquellos individuos que se definían a sí mismos como amigos de los comisarios, y que eran los recurrentes denunciantes o testigos. No obstante, hay que destacar que en todas las causas aparecen, circunstancialmente, otros sujetos que formaban parte de entramados clientelares, cuya inclusión oscurecería la delimitación del problema.

El pueblo de Choele Choel fue fundado sobre la barda norte del Río Negro, frente a la isla homónima (a la que Sarmiento denominaba la Gibraltar de la Barbarie). Ésta se encuentra ubicada en el valle medio -donde el río se divide en dos brazos- y tiene 38 kilómetros de largo por 17 de ancho, siendo su superficie de alrededor de 35000 ha de tierra fértil. Fue un antiguo asentamiento indígena, un lugar estratégico en la ruta denominada rastrillada de los cbilenos, que unía la Pampa húmeda y la Patagonia sur con los pasos transcordilleranos, por la costa del río. Allí pastoreaba e invernaba el ganado que los indios arreaban para ser comercializado en Chile.

A partir de 1879, la isla Choele Choel fue efectivamente ocupada por el ejército durante la denominada Campaña del desierto, transformándose por algunos años en acantonamiento militar. En torno a la guarnición se nuclearon otros pobladores, cuya actividad económica se habría centrado en el abastecimiento para las tropas. En las inmediaciones de la isla se fundó el pueblo Nicolás Avellaneda, que habría tenido varios asentamientos. El último, ubicado en la barda norte, al parecer data de 1882. Con el tiempo, la denominación originaria del poblado se perdió, prevaleciendo el topónimo indígena.

Choele Choel fue destinada a colonia agrícola y pastoril por un decreto federal de 1892. Pero el entonces gobernador de Río Negro, general Félix Benavides,

propuso destinarla para la crianza y engorde de ganado para el ejército e hizo levantar un censo que arrojó como resultado 346 habitantes, que ocupaban dos tercios de la isla y criaban más de 35000 cabezas de ovinos, cerca de 15000 vacunos y algo menos de equi$\operatorname{nos}^{8}$

Al ser destinada para mantenimiento de las tropas, se procedió a desalojar a los primeros pobladores que se habían asentado luego de la guerra contra el indio. Entre ellos, fue dasalojado el coronel Pablo Belisle, quien sin conocimiento del gobierno federal y del Estado Mayor del ejército, usufructuaba grandes extensiones de tierra, mediante la utilización de testaferros.

En 1898, durante la segunda presidencia de Roca, se designaría gobernador a Eugenio Tello. Al año siguiente, debido a las inundaciones que afectaron al valle inferior del Río Negro y a la consecuente destrucción de la ciudad de Viedma -capital del territorio-, las oficinas públicas se trasladaron a Choele Choel, tornándose este poblado en capital temporaria. Durante esta administración y por decreto presidencial del año 1900, la isla se destinó definitivamente para colonización agrícola, trazándose en su interior los poblados

\footnotetext{
${ }^{8}$ Vapñarsky, Pueblos, 1993, p. 289.
} 
de Lamarque y Luis Beltrán (en 1902). En ese momento, otro censo parcial de la población arrojó la cifra de 300 habitantes.

En 1899 , los rieles del ferrocarril del Sud (luego ferrocarril Roca) que unirían Bahía Blanca con Zapala, en el territorio del Neuquén llegaron a Choele Choel. La estación se emplazó a cinco kilómetros del poblado y, en sus alrededores, se construyó un caserío de madera donde residían los empleados de la empresa ferroviaria. El nuevo asentamiento creció rápidamente con la radicación de comerciantes dedicados al acopio de frutos del país y a la provisión de servicios para una población blanca fundamentalmente masculina. Se abrieron varias fondas, boliches y prostíbulos.

Entre fines de 1904 y principios de 1905 estalló una "guerra" entre dos redes de poder espacialmente localizadas. Una de ellas formada mayoritariamente por residentes del poblado originario, y la otra, por sujetos que vivían en las inmediaciones de la estación del ferrocarril (distante cinco kilómetros).

En ese momento el entonces gobernador interino, Rómulo Sarmiento, había resuelto un reordenamiento de los jefes policiales, ${ }^{9}$ en consonancia con las disposiciones de rotación temporaria de los cuadros superiores, emanadas del supremo gobierno federal. El motivo de la medida parecía ser la crisis institucional que se había produci-

\footnotetext{
${ }^{9}$ Los cuerpos policiales del territorio dependían del jefe de Policía y éste del gobernador, quedando todos los cargos subordinados al poder federal.
}

do en Choele Choel debido a la exoneración del comisario Mariano Gamboa. Así, los nuevos cargos fueron ocupados según el siguiente ordenamiento:

pasa al departamento de Avellaneda el actual comisario de la primera partida de policía volante, don Ángel Bordo y, en sustitución de éste, el comisario Eustaquio Ojeda que presta servicios en este departamento (Viedma). El comisario Busce, recientemente ascendido, pasará a la Comisaría de Roca en sustitución de don Domingo Palasciano, cuya promoción se solicita como inspector. El pase del comisario, don Justo González, del departamento de Coronel Pringles a la subcomisaria de General Conesa, departamento de Viedma y, en sustitución de éste, al subcomisario recientemente nombrado, don Roberto Bustiazo. ${ }^{10}$

Gamboa había remplazado en el año 1902 al comisario inspector Aquino Quiroga, quien en ese momento fue trasladado, y en varias oportunidades imputado por innumerables delitos de cohecho, falsificación de documentos y abuso de autoridad. Durante su estadía en Choele Choel había nucleado en torno a sí una serie de vecinos, tal como se desprende de la siguiente denuncia, elevada al juez letrado Facundo Lamarque:

Choele Choel, 3 de octubre de 1902. José María de la Cuadra, argentino, casado, de 43 años, procurador y domiciliado en este pueblo, expuso que con el comisario inspector Aquino Quiroga ha tenido siempre muy buenas relaciones, pero con motivo de la querella que a

${ }^{10}$ AHPRN, Policía, UD 1200 . 
nombre de Juan Guerrero, interpuso contra dicho Quiroga y don Arturo Casas, supo el declarante [...] que el mencionado Quiroga estaba muy irritado contra el declarante [...] que se encontró el exponente con Quiroga frente a la puerta de la casa de correos [...].

Allí recibió una provocación del comisario, e inmediatamente hizo

un telegrama al señor gobernador en estos o parecidos términos: en virtud de querella que interpuse contra el comisario don Aquino Quiroga por delitos cometidos en ejercicio de sus funciones soy objeto de provocación [...] Que en el día de ayer estando el declarante pescando en el río, se presentó el subcomisario de esta localidad ordenando al declarante que, de parte del inspector Quiroga, se presentase en la comisaría $[\ldots]$ fue a la Comisaría $[. .$.$] lle-$ gando al poco los señores [...] Pedro Vinet (ingeniero civil, argentino); Luciano Domínguez (comerciante, espanol); Francisco Lladós (comerciante, español); Cayetano Domínguez (comerciante, español), y el reverendo Domingo Anselmo.

Cuando Mariano Gamboa -argentino, de 32 años- se hizo cargo de la comisaría de Choele Choel en 1902, heredó parte de la red articulada por el anterior comisario Quiroga. Y una vez que asumió sus funciones se dedicó a las tareas rurales. Arrendó un campo de cuatro leguas cuadradas y ocupó varias chacras en la zona mensurada de la isla destinada por decreto federal, como ya se mencionó, exclusivamente para desarrollo agrícola. Pero previamente, so pretexto de tenencia indebida de animales en los predios, inició sumario y procedió a desalojar a algunos pobladores que explotaban las chacras, quienes sólo podían esgrimir como único derecho de usufructo un permiso del gobernador. ${ }^{11}$ Las actividades económicas del comisario se complementaban con el comercio de lanares y novillos. Al ser denunciado por abuso de autoridad e irregularidades en el desempeño de sus funciones se le instruyó sumario, y "[...] preguntado si se dedica al comercio con animales, dijo que no hay nada que se lo prohíba". 12

Los conflictos que se suscitaron entre el grupo de Gamboa (formado por comerciantes y hacendados) y el que lideraba, en el poblado de la estación del ferrocarril, el comerciante italiano Dionisio Gadano (formado por comerciantes, empleados $\mathrm{y}$ artesanos) dieron pie a varias investigaciones. En ellas se ventiló el prontuario del comisario:

Mariano Gamboa o Agustín Gamboa fue procesado por las autoridades de la provincia de Buenos Aires, en el año 1896, por el delito de homicidio, perpetrado en la persona de Domingo Madariaga, en el pueblo de General Sarmiento $y$, como logró fugarse, obtuvo en el año 1898, bajo el nombre tergiversado, un puesto de comisario de Policía en el distrito de Gálvez [...] habiendo la policía de Buenos Aires descubierto su paradero, solicitó y obtuvo el día 6 de febrero del año 1899 su captura [...] [permaneciendo en la cárcel] de la ciudad de La Plata hasta 1902 [...] En el año 1902, a pesar de hallarse inhabilitado por la ley, para ejercer puestos pú-

\footnotetext{
${ }^{11}$ AHPRN, Justicia letrada, exp. 469/1903.

${ }^{12}$ Ibid., exp. 4867/1905.
} 
blicos, fue nombrado comisario de Policía en este territorio [...] en el año 1905 fue exonerado por faltas graves y varios delitos que se le imputaban [...] [procesado también por] el Juzgado Letrado [...] porque siendo comisario fraguó declaraciones [...] [estuvo en la cárcel] de Choele Choel $[\ldots . .]^{13}$

Este sumario se le instruyó a Gamboa a raíz de una denuncia presentada por Dionisio Gadano, el día 30 de abril de 1905, con asesoramiento de Francisco Aybar, [juez de paz de la localidad de Valcheta]. En la instrucción sumarial seguida por el comisario Ángel Bordo a cargo de la primera partida de policía volante del territorio, avalaron la veracidad de la denuncia de Gadano:

Paride Guidi, italiano, de 31 años, casado, comerciante y domiciliado en esta localidad [...] dijo [...] ser íntimos amigos y compadres por dos veces $[. .$.$] ; Ja-$ cinto Rodríguez, argentino, de 48 años, casado, propietario y domiciliado en el quinto departamento de la Pampa Central [...], [vinculado con Gadano] comercialmente [...] Juan Ivaldi, italiano, de 42 años, casado, herrero y domiciliado en la estación de este pueblo [...]; Eduardo Machuca, oriental, de 33 años, casado, comerciante y domiciliado en este pueblo, [quien tenía con Gadano relaciones comerciales, y con Gamboa] son enemigos personales. ${ }^{14}$

\section{En la denuncia Gadano expresaba:}

dijo llamarse Dionisio Gadano, de nacionalidad italiana, de 33 años de edad, casado, comerciante y domiciliado en la

${ }^{13}$ AHPRN, Policía, UD 13945/1908.

${ }^{14}$ AHPRN, Justicia letrada, exp. 4867/1905. estación de este pueblo, quien expresó que dicho comisario notificó para que comparecieran en la Comisaría a prestar declaración a varias personas y, entre ellas, a Mariano Jamico, Mauricio García, al lesionado Juan Ramón, alias "Cullu" [...] que el comisario les exigía a estos testigos que declararan que habian presenciado que el exponente había herido a Bonifacio Torres, alias "El Mulato", cerca del palenque de la casa de negocio del exponente $y$, en caso que no lo hicieran así, los constituiría en detención por el término de dos años; que también alegó el comisario a los respectivos indígenas de ponerlos en el barro si no hacían una declaración como él les ordenaba [...] que el comisario Gamboa se encuentra distanciado con el exponente por asuntos que se relacionan con el comercio, pues dicho comisario se dedica desde hace tiempo atrás a la compraventa de hacienda como lo hace el declarante.

Continúa relatando que Gamboa le ofreció hacienda - para vender en la Pampa Central-, pero no arreglaron el precio, mencionando también una deuda de 36 pesos por un flete ferroviario de semillas que el comisario no le quiso saldar. ${ }^{15}$

En la estación del ferrocarril también tenía su comercio Francisco Villareal, "español, de 35 años, casado, comerciante" y amigo de Gamboa, quien debía sufrir continuas agresiones por parte de los amigos y parientes de Dionisio Gadano:

Choele Choel, 4 de agosto de 1905. El que suscribe, Juan Ivaldi, italiano, mayor de edad, herrero, vecino de la es-

${ }^{15}$ Ibid. 
tación de Choele Choel, se presenta.y expone: que el día 5 de junio siendo las 9 pm, más o menos y encontrándome frente a la casa de comercio del señor Francisco Villareal [...] y mientras en compañía de unos amigos nos divertíamos en quemar juguetes para festejar la despedida de un empleado del Ferrocarril, salieron de la mencionada casa de comercio los señores Villareal y José Anión, el primero armado de revólver y el segundo con sable de Caballería [...] mandé la denuncia por escrito al comisario de la localidad [...] Mariano Gamboa, quien en lugar de trasladarse al lugar del hecho [...] se vio con los dos que me atropellaron [...] de acuerdo con la citación del comisario, me presenté el día 7 en la Comisaría [...] en lugar que se me hiciera ratificar mi denuncia se me presentó un escrito para que yo lo firmase y desistiese de mi denuncia.

Testificaron a favor del relato de Ivaldi: Primo Baraldi (italiano, empleado); Enrique Gadano (italiano, comerciante, y hermano de Dionisio) y Pedro Rontio (argentino, comerciante). ${ }^{16}$

Francisco Villareal relata el mismo episodio en otros términos. Hace referencia a una reunión que, la noche del incidente, se realizó en su casa de comercio donde participaron hacendados que residían en la localidad,

que encontrábase[...] en compañia de los señores Juan Caloi, Juan Williams, Seco, Astete y muchos más cuyos nombres no recuerda[...] con motivo de ausentarse el señor Caloi para Bahía Blanca[...] y mientras estaban cenando, oyó por ahí cerca de su casa que que-

${ }^{16}$ AHPRN, Justicia letrada, exp. 5207/1905. maban cohetes $[\ldots]$ como tenía en su casa de comercio materias inflamables, y como temía que los cohetes pudieran causar algún daño a sus intereses, salió [...] divisó al sujeto Juan Ivaldi, que con miras preconcebidas quemaba cohetes y los arrojaba casi intencionalmente dentro del negocio $[\ldots]$ que en tal virtud, el sujeto Sasi Anión, dependiente de la casa que en esos momentos servía la mesa [...] agarró un cabo de piso de los que estaban en el almacén y salió fuera al encuentro del atrevido e insolente Ivaldi $[\ldots] \cdot{ }^{17}$

La anécdota finaliza con la intervención del fiscal que solicita "se informe por Secretaría si Juan Ivaldi se encuentra incluido en la lista remitida por el Ministerio de Justicia como extranjero peligroso o agitador de profesión". ${ }^{18}$

Los sumarios que se le instruyeron a Gamboa durante el año 1905 y que motivaron su exoneración, estuvieron a cargo del comisario Ángel Bordo -en ese momento, con asiento circunstancial en la localidad de Pringles-, quien una vez sancionado Gamboa, lo reemplazó en la Comisaría de Choele Choel. La investigación contra Gamboa por diferentes denuncias, provocó la movilización de las redes repercutiendo, en primer lugar, en la localidad de Pringles.

El pueblo de Pringles (hoy Guardia Mitre) se encuentra ubicado a 60 kilómetros aguas arriba de El Carmen de Patagones. Pertenecía, en ese entonces, al departamento Adolfo Alsina. Pringles se había fundado antes de la

\footnotetext{
${ }^{17}$ Ibid.

${ }^{18}$ Ibid.
} 


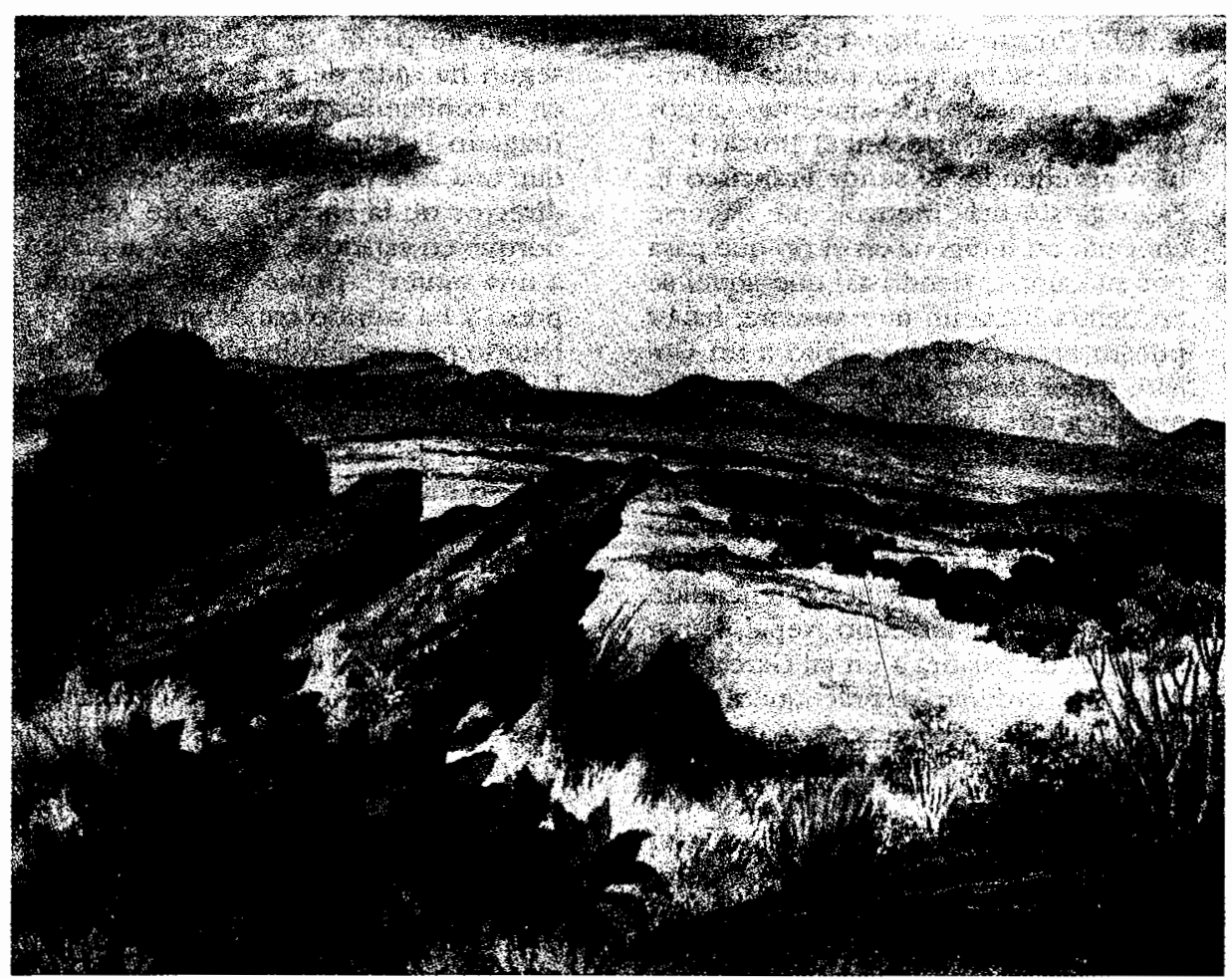

Campaña del Desierto con pobladores de El Carmen. ${ }^{19}$ Según el censo nacional de 1895, contaba con 268 habitantes.

Para censos anteriores a 1915, una mejor idea de la evolución de la población local la dan las cifras registradas para el "distrito" Pringles, que tenía límites precisos pero incluía, además del pueblo, la población de un área pequeña aunque muy fértil sobre la margen izquier-

${ }^{19}$ Por su parte, El Carmen fue fundada en 1776 en época del virreinato del Río de la Plata, con el objetivo de asentar la soberanía española en los territorios del sur. da del Río Negro: 765 habitantes en 1895,1459 en 1912,1289 en $1914 .^{20}$

A fines de 1904, ante la posible remoción de Gamboa como comisario de Choele Choel, dos comerciantes y un hacendado de Pringles remitieron una denuncia al diario La Prensa de Buenos Aires por abuso de autoridad del comisario Bordo contra sus personas. La noticia tuvo repercusión en el Ministerio del Interior:

Buenos Aires, 1 de diciembre de 1904. Señor gobernador don Eugenio Tello

${ }^{20}$ Vapñarsky, Pueblos, 1993, p. 75. 
[...] La Prensa de hoy, en correspondencia de ese territorio, publica una noticia que contiene los siguientes cargos contra el comisario Ángel Bordo [...] hizo aprehender al señor Francisco E. Faguaga sin más motivos que haberse ahogado un indigena en el río que pasa por su campo, siendo así que aquél se encuentra hacía un mes ausente; haber puesto en cepo colombiano a un Gorriti; haber intimado orden de extrañamiento a otro Gorriti pariente del anterior; haber dado de golpes a Marcial Dasso; haber aprehendido injustamente a Ramón Ferreira; haber aprehendido injustamente a Doroteo Colombo para utilizar sus caballos; haber aprehendido injustamente a Marcelino Nepal; haber ultrajado de palabra a un tal García. Sírvase $V$. S. ordenar se practiquen inmediatamente las investigaciones del caso. Rafael Castillo, ministro del Interior.

El juez letrado Luis Ruiz Guiñazú inició la investigación. En la indagatoria el comisario Ángel Bordo, argentino, de 28 años, respondió que: "Francisco Faguaga [...] fue remitido preso a la Comisaría de este punto por la de Coronel Pringles acusado de disparo de armas de fuego a Pedro Faguaga." Negó también los siguientes cargos: haber dado orden de extrañamiento a Gorriti y haber golpeado a Marcial Dasso. Continúa:

que a raíz de haberse recomendado la captura del sujeto Pedro Páez, acusado de heridas en Valcheta al señor comisario Costa, una noche como el declarante no le constara quién fuera el sujeto Ferreyra y coincidiendo la filiación de éste con la de Páez, lo detuvo hasta tanto practicaba las investigaciones [...] que aprehendió a Marcelo Nepal [...] una noche como a las 11 lo detuvieron en un despacho de bebidas [...] que según ha oído decir que se domicilia en la confluencia donde es alguacil del Juzgado Letrado del Neuquén $[\ldots]$ y que una sola vez ha estado detenido el director de la cárcel, Vicente Aguilar, porque en estado de ebriedad abofeteó a una mujer[...] que Nepal ha estado preso $y$ ha sufrido condena en este territorio por encubridor de varios delitos $[\ldots]$ entre ellos el hurto de animales [...] el corresponsal viajero de La Prensa es el sujeto José Cámpora, persona que por su mala conducta $y$ antecedentes no hace mucho tuvo que fugar del territorio del Neuquén; que tanto éste como Juan Vichich, corresponsal de $L a$ Prensa en Viedma, están estrechamente vinculados con Francisco Gorriti alias "Pachi" y los Faguaga y otras familias de este territorio por lazos de parentesco, y que en estas acusaciones sólo existe un deseo de venganza contra el declarante en virtud que ha procesado al mencionado "Pachi", Francisco Faguaga y Nicolás Rolé; al primero por hurto de animales, al segundo por defraudación de corderos a la testamentaria de $S$. Kincaid y al tercero por haber remitido a Patagones cueros fuera de la guía $y$ contraseñalados $[\ldots]^{21}$

Esta causa que se inició en Pringles, continuó con declaraciones de prominentes vecinos de Choele Choel. Todos los que declararon en esta oportunidad formaban parte del grupo opositor al comisario Gamboa, quienes se nuclearon posteriormente en torno del comisario Bordo, una vez que éste se radicó en el lugar. Las declaraciones testimoniales a favor del comisario Bordo corresponden a: "Juan Pedranti, italiano casado de 34 años, domiciliado en

${ }^{21}$ AHPRN, Justicia letrada, exp. 4904/1904. 
Choele Choel", quien afirma que "el comisario ha sido siempre muy correcto y en el desempeño de su puesto, muy enérgico $[. .$.$] que solamente se$ han quejado [...] aquellas personas que no han podido hacer lo que se les ocurría". Declaraciones en el mismo sentido son las de Luisa M. de Pedranti -italiana, esposa del anterior-, José Bares -español, comerciante. Finalmente, consta la exposición de la mujer golpeada por el director de la cárcel,

Segunda Ibarra, argentina, de 17 años, soltera, de profesión las de su sexo [...] que se negó a declarar [...] en virtud de que el comisario [...] Mariano Gamboa le dijo que no declarara sin previa orden de él.

El caso termina con la actuación del fiscal Guglialmeli pidiendo el sobreseimiento definitivo del comisario Bordo porque "no he hallado demostrada la verdad de las denuncias consignadas en el telegrama de fojas $1 ", 22$ que enviara el ministro del Interior y que motivó la apertura de la causa.

A partir del momento en que es exonerado Gamboa en 1905 y Bordo se hace cargo de la Comisaría de Choele Choel, y cuando los dos sectores están claramente perfilados, se suceden una serie de juicios, querellas y acusaciones, todos bajo la carátula de abuso de autoridad, lesiones y agresiones. Una de las denuncias:

Choele Choel, 2 de setiembre de 1906. Al señor juez letrado del territorio, Alfredo Torres[...] Manuel Seco, ciudadano español, de 54 años de edad y

${ }^{22}$ Ibid. con 26 años de residencia en el país, casado, comerciante, me presento pidiendo justicia y castigo para el comisario de Policía, don Ángel Bordo, el que acompañado de un sargento y un gendarme atropelló mi casa de comercio, sacándome a golpes y empujones me condujo a la Comisaría y me encerró en un inmundo calabozo sin permitir se me diese agua y comida, todo por haber cometido el grave delito, según él, de haber tocado auxilio llamando a la policía para que redujese a prisión a un individuo que, puñal en mano, amenazaba en la calle a las personas que se encontraban en mi casa de comercio. [Más adelante agrega que Ângel Bordo lo condujo a la comisaria diciendo] que iba a arruinar a todos los amigos de Gamboa. ${ }^{23}$

En otros expedientes, Mariano Gamboa personaliza la confrontación firmando siempre como ex comisario:

[...] comunico a usted [el jefe de Policía] que el comisario Bordo viene amenazándome públicamente; anoche después de cometer un atropello con un comerciante español por el solo hecho de ser mi amigo, manifestó a grandes voces que no pararía hasta que me arruine a mí y a todos los que cometen el delito de ser mis amigos; por esta razón pido al señor jefe garantías para mi vida e intereses, pues las manifestaciones del comisario es determinar que no las tengo, y puede suceder que una tropelía que el comisario cometa conmigo, dé lugar a un hecho grave que trato siempre de evitar[...]. [En el mismo expediente, el juez de paz suplente, Leopoldo Murguía, pide protección al jefe de policía pues] el comisario

${ }^{23}$ AHPRN, Justicia letrada, exp. 532/1906. 
Bordo manifiesta públicamente que no parará hasta arruinar a Gamboa y todos sus amigos; yo, siendo uno de ellos, me veo en la necesidad de creer que no tengo garantías con este funcionario. ${ }^{24}$

También en el mismo expediente Sebastián Scarcellato, italiano y dueño de un prostíbulo, acusa al comisario por abuso de autoridad: "se me tortura en la barra y tengo mis intereses abandonados". En la indagatoria, Bordo afirmó que mantenía a Scarcellato en la

barra de seguridad [...] primero porque carecía de personal para la custodia [...] segundo, por la escasa o ninguna seguridad de esta Comisaría, y tercero, porque Scarcellato, como otros, a altas horas de la noche tenía por costumbre, aprovechando que el único agente de servicio se dormía, a salir y venir recién al amanecer, ocurriendo el casó, que una noche el declarante entró en la pieza que sirve de calabozo y encontró que en la cama de Scarcellato había un muñeco figurando un hombre durmiendo; que descubierta esta estratagema por el declarante, se dirigió al prostíbulo que este sujeto había tenido la audacia de establecer en esta localidad, y al llamado salió Scarcellato, al que condujo a la Comisaría [...] en virtud de los tantos hechos ocurridos en la casa de Scarcellato se vio obligado a mantener vigilancia. [Y agrega que] el señor juez letrado del territorio hizo notar al señor gobernador, en oficio número 377 de fecha marzo 16 del corriente año, el porcentaje de los hechos que ocurrian en Choele Choel o eran o tenían origen y se desarrollaban en la casa del referido sujeto. ${ }^{25}$

\footnotetext{
${ }^{24}$ Ibid., exp. 5716/1906.

${ }^{25}$ Ibid.
}

En 1907 la guerra continúa, Gamboa eleva al juez letrado en un mismo expediente tres denuncias contra la policía de Choele Choel y el comisario Bordo, donde se observa por inversión de los motivos cuáles eran las causas fundamentales del conflicto. Eran por presunto homicidio por desaparición de un indígena y porque le impedían ocupar un campo de cuatro leguas del que era arrendatario.

En la primera afirma que recibió el siguiente anónimo:

el comisario con su policía le han pegado un balazo a un individuo y lo han traído a la cuadra de ellos y de allí lo sacaron y lo llevaron al panteón y lo han enterrado vivo según creo del modo que está sentado o doblado medio abajo de la simiente del corralón [...] tiene una cruz chiquita, al ver la sepultura parece de un angelito $[. .$.$] los pre-$ sos han sentido los clamores [...] uno de los presos que ellos malician que los puede descubrir, el comisario le dijo que si andaba jodiendo que le harían lo mismo $[\ldots]$ que yo sé que en el pueblo han desaparecido un Magallanes y un Segundo Biba[....$^{26}$

En la segunda menciona la desaparición de un peón indígena, y en la tercera afirma:

[...] soy arrendatario de cuatro leguas de campo en este departamento, de propiedad del doctor don Mariano Marcó [...] el comisario de policía, abusando de su autoridad, violentándome me impide penetrar dentro del terreno[... ${ }^{27}$

\footnotetext{
26 Ibid., exp. 731/1907.

${ }^{27}$ Ibid.
} 
Pero, el comisario Ángel Bordo fue sobreseído en estas causas, como en todas las imputaciones que sus enemigos le hicieran por abuso de autoridad. Sólo en 1912, el juez letrado le dictó prisión preventiva por haber cometido errores de procedimiento al momento de instruir sumario contra un joven de la localidad de Río Colorado, acusado de rapto por la madre de su novia. ${ }^{28}$ En este juicio afirmó

[...] que se le han instruido varios sumarios, cuyo nombre no recuerda, por los jueces señores Ruiz Guiñazú, Lamarque y Torres, desconociendo su resultado por no haber sufrido ninguna detención $[\ldots]]^{29}$

Los datos que iluminan la dimensión espacial de la confrontación, se complementan con otras causas que, para los mismos años, corresponden a la localidad de Valcheta. Ésta se encuentra situada al sur del territorio de Río Negro sobre la denominada Línea Sur, vía ferroviaria que, partiendo del puerto de San Antonio Oeste en el golfo San Matías y atravesando la meseta patagónica, llegó a Bariloche en 1934. Las puntas de rieles de este ferrocarril -que en su origen se construyó con capitales estatales, de acuerdo con la Ley de Fomento de Territorios Nacionales (5.559/1908)- alcanzaron Valcheta en 1909.

Por su condición de oasis ubicado en la desértica meseta, las poblaciones

${ }^{28}$ El rapto amoroso era una costumbre muy difundida en la zona, y la antesala de un matrimonio no consentido por los padres de la joven.

${ }^{29}$ AHPRN, Justicia letrada, exp. 9552/1912. indígenas la eligieron como punto estratégico de la ruta que desde el sur se dirigía a empalmar el camino de los cbilenos. Allí se fundó Fuerte Alsina en 1883 , origen del actual pueblo.

En 1886 se hallaban radicados en este oasis algunos centenares de indígenas tehuelches, que años después emigraron. Reemplazando a esa población tehuelche, se radicaron ya en este siglo indios araucanos procedentes de Chile, y también indios que emigraron del territorio de La Pampa. ${ }^{30}$

En la documentación que hace referencia al caso que se está relatando, se puede observar que en 1904 el juez de paz de esa localidad, Francisco Aybar-defensor en varias causas del comerciante italiano Dionisio Gadano, radicado en la estación del ferrocarril de Choele Choel-, solicita al juez letrado, Luis Ruiz Guiñazú, envíe al comisario Bordo para que investigue una serie de delitos cometidos por el inspector Aquino Quiroga:

[...] que tanto el inspector Quiroga, como el comisario, señor Martínez, ejercen una gran influencia en la mayor parte de los comisarios de policía y dado el celo, la competencia y la rectitud de los procederes del señor comisario Bordo, [lo] indico como el funcionario más a propósito para la investigación. ${ }^{31}$

Esta no era, al parecer, la opinión de un grupo mercantil de El Carmen vinculado al periódico local La Nueva Era. Este periódico no cesaba de des-

\footnotetext{
${ }^{30}$ Vapñarsky, Pueblos, 1993, p. 81.

${ }^{31}$ AHPRN, Justicia letrada, exp. 4788/1904.
} 
tacar la figura del comisario Quiroga, a pesar de las recurrentes imputaciones por cohecho y abuso de autoridad. En la nota "La policía del territorio", publicada en 1910, se lee:

El gobernador interino, señor Galíndez, ha dispuesto que el inspector de Policía, don Fermin Cuestas, practique una visita de inspección a varias comisarías del territorio [...] Hubo un tiempo hace seis o siete años, que las comisarías de policía funcionaban regularmente y su personal se desempeñaba con celo y actividad casi sin excepción saliente. Era entonces inspector el malogrado Aquino Quiroga, cuya energía, laboriosidad y profundo conocimiento del mecanismo policial le permitían realizar inspecciones periódicas de cuya eficacia hay pruebas indudables en los archivos de la gobernación y de la Jefatura de Policía. Pero faltó Quiroga en la inspección; la jefatura anduvo en manos ineptas y entonces se inició el desbarajuste reinante, de donde resultan los comisarios vandálicos y los indolentes, cuando no incapaces de cumplir su misión siquiera mediocremente $[\ldots]^{32}$

La confrontación discursiva refleja el entramado de poder. Así, todos los conflictos que estallaban debido a la puja de intereses en cada localidad, repercutían en el territorio según la amplitud de las redes de solidaridad. En este relato mínimo puede observarse que, a nivel de los agentes estatales, la extensión de la red de Bordo incluía al juez de paz de Valcheta y al comisario de Pringles, Héctor Guffan-

${ }^{32}$ Museo Histórico del Carmen de Patagones (en adelante MHCP), La Nueva Era, 30 de octubre de 1910. ti. Mientras que la red que articulaba Gamboa incluía al comisario inspector, Aquino Quiroga.

\section{LA CONSTRUCCIÓN DEL ORDEN}

Para comprender las confrontaciones y el tipo de vinculaciones sociales que ellas expresan, fue necesario superar una serie de obstáculos en cuanto a la selección de la información y a la delimitación de los problemas. Pero fundamentalmente, abordar la impermeabilidad de una producción y circulación discursivas coetáneas de los acontecimientos que fueron construyendo una imagen sólida de desorden endémico en el territorio.

La editorial del periódico local $L a$ Nueva Era del 1 de agosto de 1909, sintetiza los lineamientos generales del discurso que lentamente iba constituyéndose en imagen hegemónica.

Es que, francamente, la policía de Río Negro, con excepción de dos o tres comisarios, no es tal policía sino una comandita cuyo jefe, antiguo comisario, tiene todas las características de la venalidad más declarada[...] Conste que no nos guía ningún espíritu de hostilidad a la policía. Desde dos años a ésta, acá venimos predicando de forma semejante, sin obtener el menor resultado favorable, sea por debilidad o negligencia de las autoridades superiores, lo cierto es que hasta el mismo jefe de la repartición anda envuelto en negocios que redundan en perjuicio del buen nombre de esa rama de la autoridad. Y de tal manera es exacto, que jamás como actualmente se ha visto descuidada la vigilancia de la campaña, donde hoy se roba y se juega co- 


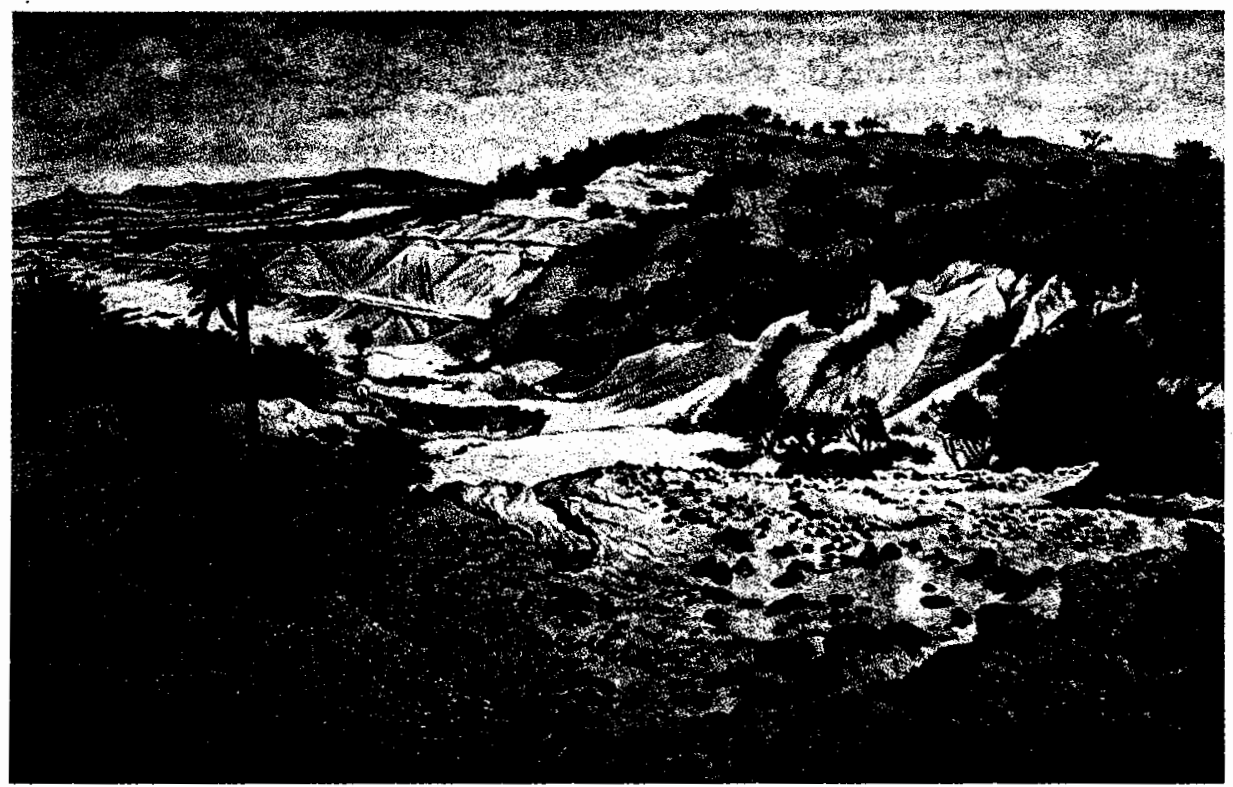

mo nunca, sin dar con los malhechores [...] Los diarios bahienses han registrado, en estos últimos meses, sesudos artículos de fundada crítica demostrando la incapacidad de la policía rionegrina; pero ellos ignoran que muchos agentes de esta repartición están adscritos a una obra meritoria que nada tiene que ver con sus funciones policiales, están destinados a cuidar ovejas que su jefe posee en distintos lugares [...] habiéndolas adquirido a precios ínfimos en los remates de sucesiones vacantes con la tolerancia de los rematadores infieles y teniendo asegurada la complaciente aprobación del juez para el inicuo negocio[...] Salvo dos o tres comisarios cuyos nombres han figurado honrosamente en estas columnas, lo demás está carcomido $[\ldots] .^{33}$

${ }^{33}$ MHCP, La Nueva Era, 1 de agosto de 1909.
Así, para comprender estas confrontaciones, fue necesario, en primer lugar, situarlas en el contexto de la conflictividad general -diferenciando sus particularidades $-y$, en segundo lugar, tomar distancia de las configuraciones que las fuentes ofrecen para la elaboración de relatos históricos circunscritos a un enfoque a ras del suelo. Dicho en otros términos, intentar una explicación de los conflictos a partir de la comprensión de las relaciones sociales en diferentes planos: en la forma que éstas se presentan en el juego de poder local y cotidiano, y en el significado que las mismas asumen en la dinámica del contexto social de dominación en que se inscribieron.

En el juego cotidiano de poder, en que todos los sujetos actúan con arreglo a fines, las confrontaciones sociales 
y étnicas expresadas políticamente, asumen siempre la forma de conflictos personales. Y se muestran como escenas de boliches; riñas en los prostîbulos; aparición esporádica de indígenas que recalaban en los poblados y que huían ante el menor escándalo; presencia de forasteros sospechosos, bandoleros, vagos y malentretenidos; violación o rapto de alguna mujer; apremios ilegales; juegos de pirotecnia nocturnos para intimidar a los adversarios; pujas por controlar las oficinas de correos y de la justicia de paz; fugas a caballo después de haber baleado la calle principal; demostraciones de fuerza de los comisarios y algunos de sus amigos pretendiendo imponer el orden en el pueblo con su sola presencia.

Dicho de otra manera, si nos centramos solamente en la reconstrucción de las actitudes individuales de los personajes implicados, cada confrontación y su resolución se presenta -según el papel que los implicados asumen- como una instancia progresiva en la conformación de poderes personales. En efecto, en las diferentes construcciones discursivas, el territorio de Río Negro aparece fracturado en espacios subordinados a los comisarios y sus respectivas camarillas, agentes de un orden discrecional contra el cual el poder federal mostraría una recurrente impotencia.

Pero en el contexto social de dominación en que se inscriben, las relaciones de poder expresan sectores sociales en proceso de constitución; luchas corporativas; reconocimiento explícito del papel arbitral de la justicia y del gobernador en tanto instancia superior resolutiva; elaboración de discursos éticos ${ }^{34}$ frente a la intromisión del Estado federal y a la imposición de las reglas del mercado capitalista, y redes que al estar articuladas por un funcionario, al mismo tiempo que permitían consolidar los poderes personales, posibilitaban la injerencia de las instituciones federales. Asimismo, es importante señalar la utilización que los sujetos implicados en los conflictos hacían de los medios de comunicación de circulación nacional: una forma de apelación suprema al gobierno federal residente en Buenos Aires.

Un tercer plano que comprende al contexto de dominación es el papel que jugó la política federal en el proceso de construcción del orden. Las noticias alarmantes y recurrentes de las que se hacía eco la prensa local y nacional implicaron siempre una rápida intervención del Ministerio del Interior, situación que provocaba la adopción de medidas estratégicas para el reordenamiento administrativo. En este sentido, durante la segunda presidencia de Julio Argentino Roca comenzaron a ejecutarse políticas conducentes al afianzamiento de la dominación mediante el desarrollo de prácticas judiciales tendientes a la construcción de un orden hegemónico, constituyéndose los fiscales -en su mayoría profesionales jóvenes imbuidos de la doctrina liberalen el brazo ejecutor del poder civil.

${ }^{34}$ Por ejemplo, cuando el gobernador permitió, a principios del siglo $\mathrm{xx}$, la radicación de prostíbulos que se proveían con las prostitutas que abastecían los circuitos nacionales, los vecinos decentes de las diferentes localidades comenzaron a elaborar un discurso moralista en contra de la medida, porque los bolicberos y dueños de fonda veían perjudicado su negocio. 
En este marco político, son más que frecuentes las cartas y telegramas que el entonces ministro del Interior, Rafael Castillo, le enviaba al gobernador interino de Río Negro, Rómulo Sarmiento, en las cuales le expresaba las prescripciones de la política que debía seguirse. Una carta de octubre de 1905 es en este sentido paradigmática:

[...] para recordarle los propósitos del señor presidente de la república de hacer efectivas las garantías de orden, de seguridad y justicia en los territorios [...] [es necesario] servir al bien público y levantar el prestigio de la autoridad para que las poblaciones tengan confianza en la justicia $[. ..]{ }^{35}$

Se pretendía disciplinar a las fuerzas policiales, pero fundamentalmente se intentaba delimitar el papel de los aparatos de Estado. Una vez finalizada la guerra contra el indio, el ejército sólo intervendría en los conflictos mayores cuando el gobierno determinase que existía amenaza de conmoción interna. ${ }^{36}$ Por tanto, el tipo de conflictos como los que hemos relatado -y aunque jaqueasen constantemente el orden que pretendía imponersedebían ser resueltos por la justicia. La aplicación de justicia debía constituirse en la instancia fundamental que limase las arbitrariedades de la policía y

\footnotetext{
${ }^{35}$ AHPRN, Policía, UD 010134, octubre de 1905, telegrama firmado por el ministro del Interior Rafael Castillo.

${ }^{36}$ Recuérdese el papel que jugó el ejército durante las huelgas de los peones rurales del sur de la Patagonia, a principios de la década de 1920, diez años después de los conflictos que estamos relatando en este trabajo. Véase Bayer, Patagonia, 1986.
}

la administración, tornándose en la pieza clave para la construcción del consenso.

\section{CONCluSIONES}

A partir del caso estudiado se puede inferir que no se puede limitar el análisis de la constitución del Estado-nación argentino a las negociaciones históricas entre los diferentes sectores de elite, herederos de la tradición colonial, quienes se habrían modernizado hacia finales del siglo XIX, como consecuencia del auge agroexportador. Según estas visiones, la centralización del poder y la consolidación de la nación se habrían logrado alrededor de $\mathbf{1 8 8 0}$, dando por resultado un modelo de país unificado en torno a su elite dirigente. En el caso argentino, el cuadro modernizador se completa, frecuentemente, con la superación de la fórmula alberdiana -república abierta/república restrictiva- partiendo de la obligatoriedad y el secreto de sufragio que estableció la ley electoral Sáenz Peña de 1912.

Ahora bien, en este tipo de análisis se han desatendido otra serie de cuestiones que permiten comprender las diferentes mediaciones y articulaciones de la dimension estatal, por ejemplo los sectores dirigentes regionales y locales, los cuales juegan un papel decisivo en la construcción y el mantenimiento del orden, y en el control social de los sectores subalternos. Claro está que dichos órdenes locales se tornarán, con mucha frecuencia, intrínsecamente funcionales y contradictorios con los diferentes niveles de organización del Estado, tanto por la com- 
petencia de las jurisdicciones, como por los diferentes intereses que se ponen en juego.

En el marco de esta perspectiva de análisis de la realidad política, y con el fin de comprender las diferentes instancias de mediación del poder que caracterizan la forma Estado, se ha analizado el proceso de constitución de los sectores dominantes locales en un área marginal, como era la Patagonia a principios del siglo XX. Y como resultado de la investigación, se pudo observar que en su conformación jugó un papel decisivo el ejercicio de la violencia; dimensión que encerraba en sí misma la principal contradicción con los poderes federales.

En efecto, la centralización estatal lleva implícito, necesariamente, el control de la violencia por parte de los organismos gubernamentales y judiciales. Pero la conquista de los territorios patagónicos, realizada por el poder de las armas, permitió la pervivencia de las prácticas cotidianas que se habían hecho habituales como consecuencia de la militarización del espacio. La dispersión de la violencia en manos privadas era justificada con diferentes excusas y criterios ideológicos: miedo a la sublevación o venganza indígena; temor al bandolerismo; defensa de la propiedad y el territorio frente a los intrusos y usurpadores, etc. Más aún, el Código Rural de los Territorios Nacionales, sancionado en 1894 , permitió la posesión privada de armas, estando prohibida la ostentación de las mismas.

En este contexto, se tornó difícil mantener la disciplina, sobre todo debido a la falta de profesionalización de los sectores policiales, pues éstos funcionaban como el brazo armado de los intereses locales. También, tal como se desprende de los documentos, los cuadros altos del arma tenían intereses económicos privados y utilizaban su posición de agentes estatales para dirimir las oposiciones que pudiesen presentárseles en la consecución de los propios fines. No obstante, contrariamente a lo que pudiese suponerse, no estamos en presencia de la anulación de la forma Estado o en el absoluto dominio de los poderes personales.

La tarea desarrollada por los gobernadores, y sobre todo por los jueces y fiscales de la justicia letrada, posibilitaban que las redes de poder se desarticulasen o entrasen en contradicción. Para ello, se utilizaron diferentes estrategias con el fin de encuadrar la acción de los cuadros superiores de la Policía en torno de quienes afirmaban las redes de poder. Así, las medidas que se tomaban en consecuencia iban desde las más simples, como el apercibimiento o la sanción, a las más contundentes, como el traslado, la exoneración o el enjuiciamiento.

También, el tipo de conflictividad estudiada permite observar, en uno de los planos, cuáles fueron los comportamientos sociales durante el primer estadio de formación de los sectores dominantes locales en Norpatagonia, en momentos en que se estaban definiendo sus intereses corporativos. Sin lugar a dudas, su momento histórico de constitución tardía presentó un desfasaje con el grado de bomogeneidad, de autoconciencia y de organización ${ }^{37}$

${ }^{37}$ Véase Gramsci, Política, 1993, p. 112. 
alcanzado por los sectores dominantes a escala nacional.

En otro plano, es posible visualizar que el poder federal, en su forma Estado y en los aparatos de dominación, se constituyó, a pesar de todo, en el arbitrio de las confrontaciones regionales. Los presupuestos del interés general -ideología dominante en la concepción contractualista del podereran puestos en práctica mediante la aplicación de justicia y la amenaza de coacción. De esta manera, los aparatos de dominación, a la vez que se iban constituyendo como tales en los nuevos espacios conquistados, tuvieron la capacidad para negociar o desarticular aquellos intereses contradictorios que emergían como amenazas para el orden general.

En este entramado social, surcado por antagonismos que asumían una forma personalizada y que se ponían en juego cotidianamente, la resolución dinámica de los conflictos fue secretando un orden en permanente renegociación, tanto en el plano local como entre éste y la política federal. Y los sujetos implicados en las disputas se constituyeron como tales en el discurso y en la práctica de poder que se ponía en juego día a día, configurando al mismo tiempo su propia reproducción a partir del ejercicio del mando y de la definición e imposición de las reglas de juego.

\section{ARCHIVOS}

AHPRN Archivo Histórico Provincial de Río Negro.
MHCP Museo Histórico de Carmen de Patagones.

\section{BIBLIOGRAFÍA}

-Argeri, María E. y Sandra Chia, "Resistiendo a la ley: ámbitos peligrosos de sociabilidad y conducta social. Gobernación del Río Negro, 1880-1930", Anuario IEHS, núm. 8, 1993, pp. 275-306.

-Bayer, Osvaldo, La Patagonia rebelde, Hyspamérica, Buenos Aires, 1986.

-Bonaudo, Marta y Elida Sonzogni, "Redes parentales y facciones en la política santafecina, 1850-1900", Siglo XIX. Revista de Historia, núm. 11, ene.-jun., 1992, pp. 74-110.

-Graham, Richard, Patronage and politics in nineteentb-century Brazil, Stanford University Press, Stanford, 1990.

-Gramsci, Antonio, La política y el Estado moderno, Planeta/Agostini, Madrid, 1993.

-Guerra, François-Xavier, México del Antiguo Régimen a la revolución, Fondo de Cultura Económica, México, 1988, 2 vols.

-Mallon, Florencia, Peasant and nation: the making of post-colonial Mexico and Peru, University of California Press, Berkeley, 1995.

-Rendón Garcini, Ricardo, El prosperato: Tlaxcala de 1885 a 1911, Siglo XXI Editores, México, 1993.

-Sábato, Hilda, "Ciudadanía, participación política y la formación de una esfera pública en Buenos Aires, 1850-1880", Siglo XIX. Revista de Historia, núm.11, ene.jun., 1992.

-Thomson, Guy, "Popular aspects of liberalism in Mexico, 1848-1888", Bulletin of Latin American Research, vol. X, núm. 3, pp. 265-292.

-Vapñarsky, César, Pueblos del norte de la Patagonia, Editorial de la Patagonia, Fuerte Roca, 1993, p. 289. 


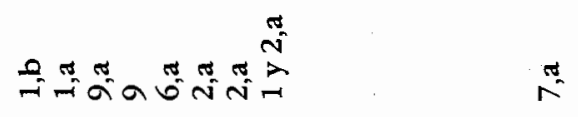
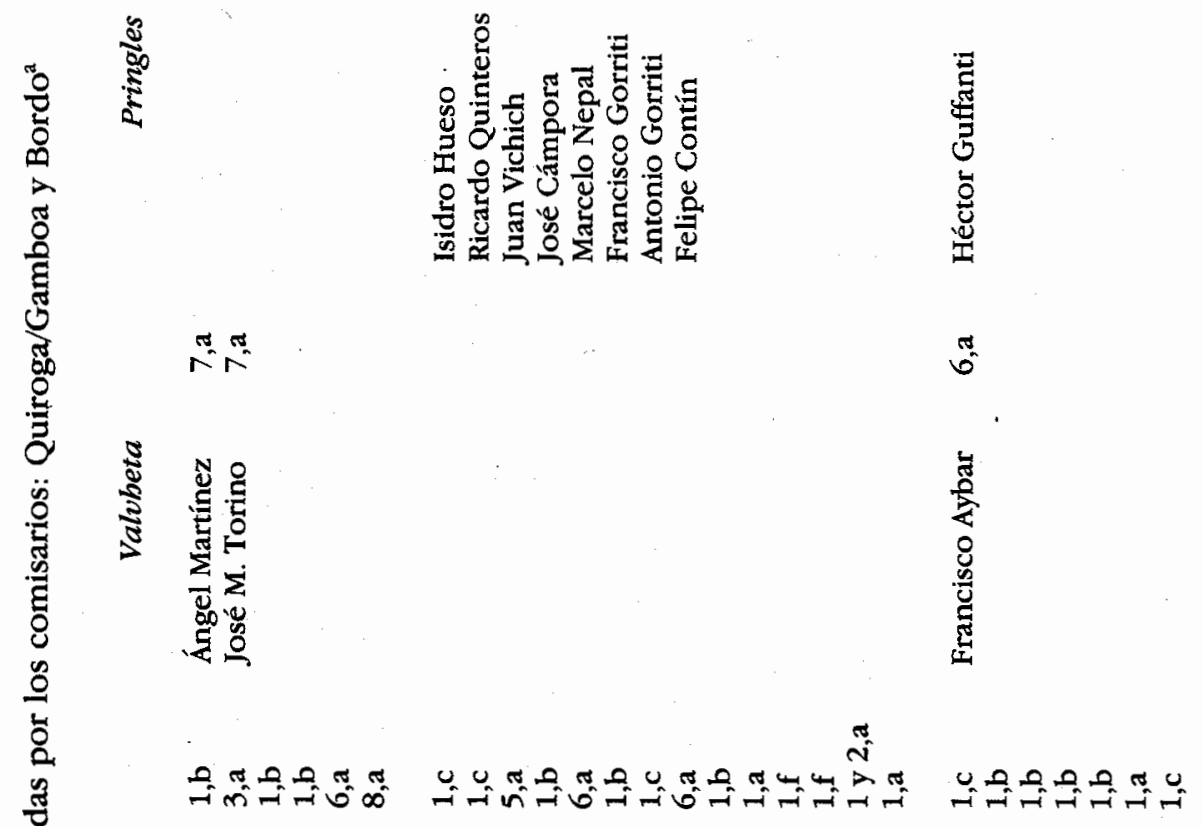

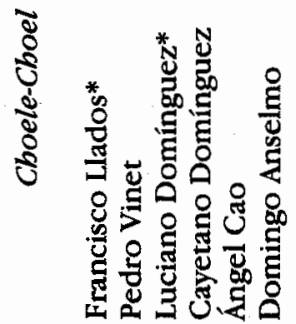
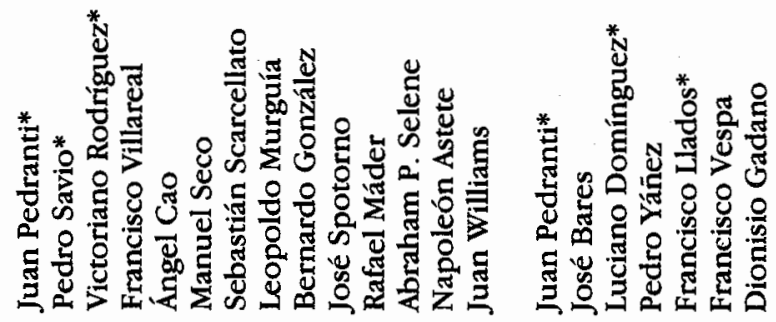

율

हึ

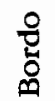




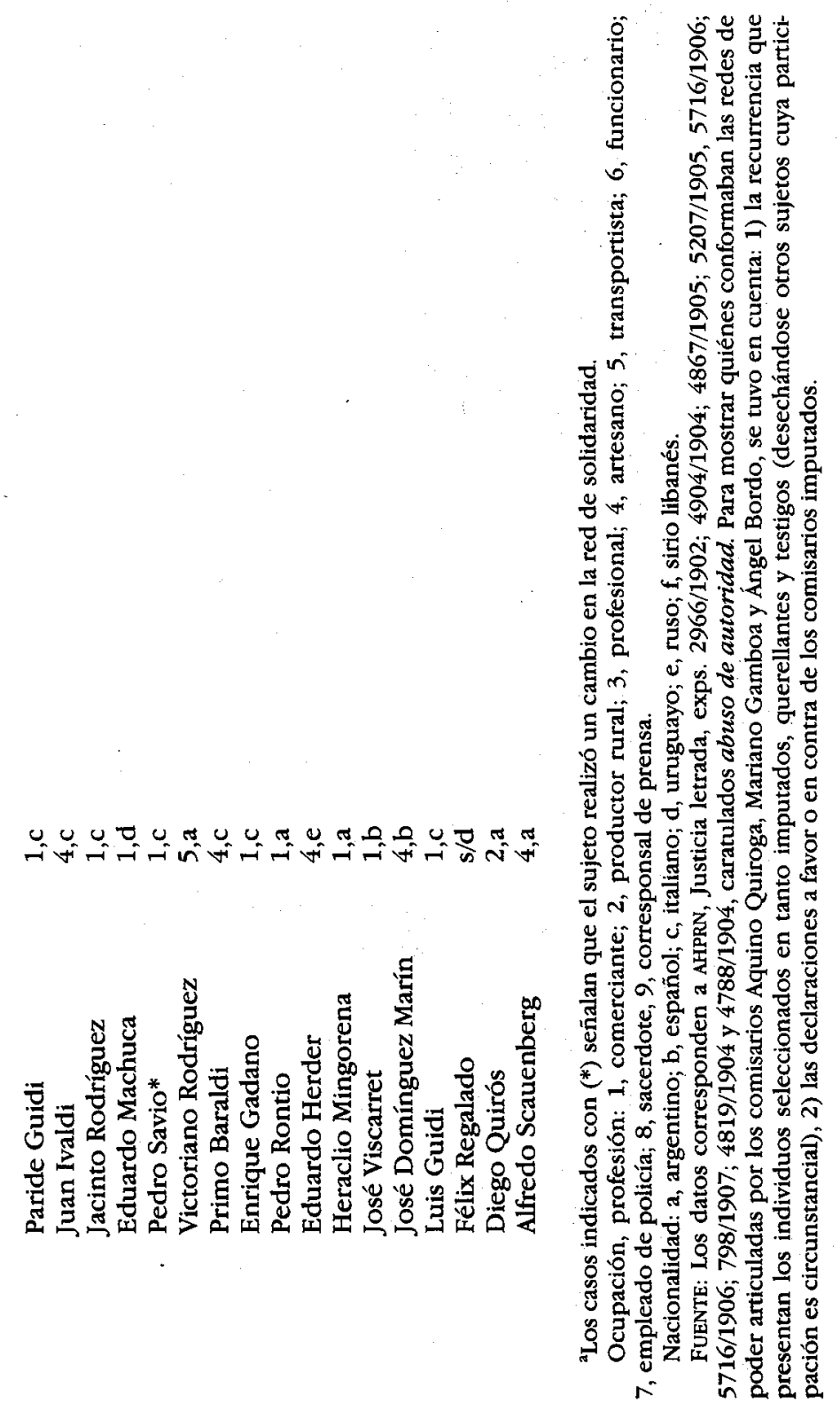




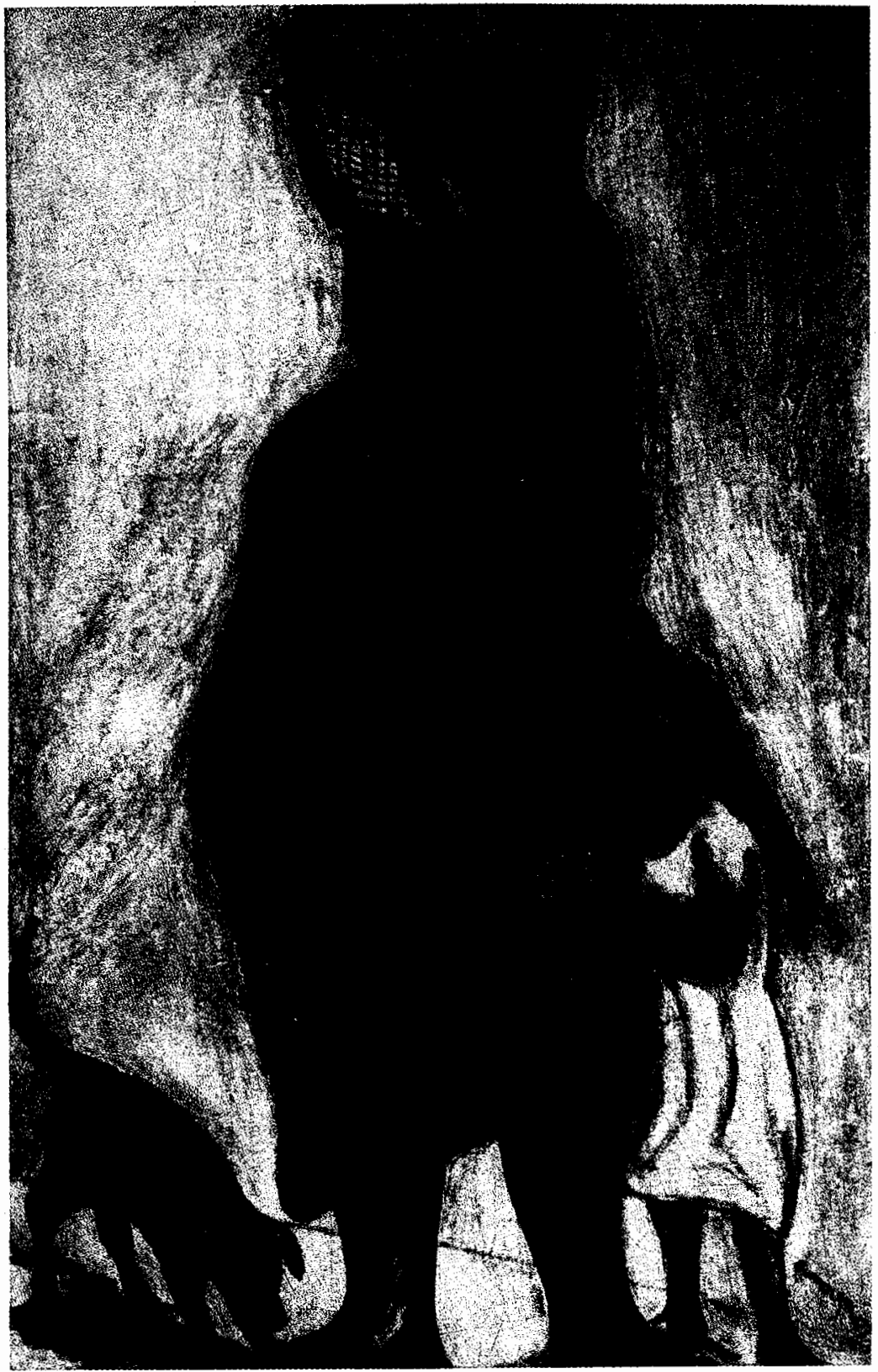

